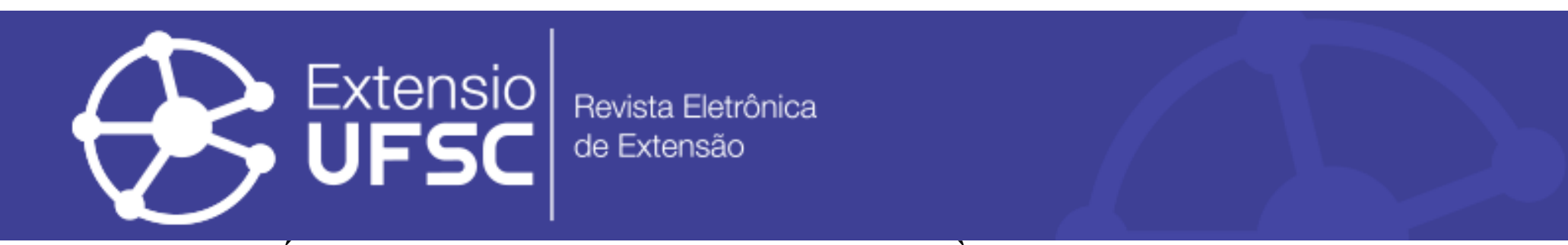

\title{
PRÁTICAS EXTENSIONISTAS RELACIONADAS À LIBRAS COMO L2 PARA OUVINTES: RELATO E AVALIAÇÃO DA EXPERIÊNCIA
}

\author{
Lídia da Silva \\ Universidade Federal do Paraná \\ lidiaufpr@gmail.com \\ Suélicy Anaiane Vidal de Souza \\ Universidade Federal do Paraná \\ anayane1986@gmail.com
}

\begin{abstract}
Resumo
O presente trabalho tem o objetivo de relatar e avaliar as práticas extensionistas da área de Libras como segunda língua (L2), para ouvintes que são desenvolvidas no âmbito da Universidade Federal do Paraná (UFPR). Para tanto, relata a articulação das várias ações extensionistas realizadas de 2016 a 2021 no Programa chamado Núcleo de Ensino de Libras (NEL) e as avalia a partir da perspectiva analítica proposta por Cristofoletti e Serafim (2020). Na parte do relato, apresenta os cursos, os eventos, os projetos e os produtos desenvolvidos pelo NEL e na parte da avaliação analisa quem faz, a quem se destina, a materialização, os objetivos e os impactos das atividades extensionistas. Conclui que as práticas extensionistas ocorrem de forma conjunta e combinada e que têm demonstrado resultados significativos que colaboram com o desenvolvimento da área.
\end{abstract}

Palavras-chave: Extensão Universitária; Libras; L2.

\section{EXTENSIONIST PRACTICES RELATED TO BRAZILIAN SIGN LANGUAGE AS L2 FOR LISTENERS: REPORT AND EVALUATION OF EXPERIENCE}

\begin{abstract}
The present work aims to report and evaluate the extension practices in the field of Libras as a second language (L2) for listeners that are developed within the scope of the Federal University of Paraná (UFPR). For this purpose, it reports the articulation of the various extension actions carried out from 2016 to 2021 in the Program called Núcleo de Ensino de Libras(NEL) and evaluates them from the analytical perspective proposed by Cristofoletti and Serafim (2020). In the report part, it presents the courses, events, projects and products developed by the NEL and, in the evaluation part, it analyzes who does it, who it is intended for, the materialization, objectives and impacts of extension activities. It concludes that extension practices occur in a joint and combined way and that they have shown significant results that collaborate with the development of the area.
\end{abstract}

Keywords: University Extension; Brazilian Sign Language; L2.

\section{PRÁCTICAS EXTENSIONISTAS RELACIONADAS CON LIBRAS COMO L2 PARA OYENTES: INFORME Y EVALUACIÓN DE EXPERIENCIA}

\section{Resumen}

El presente trabajo tiene como objetivo informar y evaluar las prácticas de extensión en el campo de Libras como segundo idioma (L2) para oyentes que se desarrollan en el ámbito de la Universidad Federal de Paraná (UFPR). Para ello, informa la articulación de las distintas acciones de extensión realizadas de 2016 a 2021 en el Programa Núcleo de Ensino de Libras (NEL) y las evalúa desde la perspectiva analítica propuesta por Cristofoletti y Serafim (2020). En la parte de informe presenta los cursos, eventos, proyectos y productos desarrollados por la NEL y, en la parte de evaluación, analiza quién lo hace, a quién va dirigido, la materialización, objetivos e impactos de las actividades de extensión. Se concluye que las prácticas de extensión se dan de forma conjunta y combinada y que han mostrado resultados significativos que colaboran con el desarrollo del área.

Palabras clave: Extensión Universitaria; Libras; L2. 
Práticas extensionistas relacionadas à Libras como L2 para ouvintes: relato e avaliação da experiência

\section{INTRODUÇÃO}

Em 2014, cinco professores surdos ingressaram na Universidade Federal do Paraná (UFPR) para atender à demanda da disciplina de Língua Brasileira de Sinais (Libras) que, segundo o Decreto 5626/2005, é obrigatória a todas as licenciaturas. À época, o professor Marcelo Porto oferecia cursos de Libras, na modalidade de extensão, à comunidade interna da Universidade Federal do Paraná (UFPR), atendendo servidores e estudantes. Posteriormente, em 2015, houve a abertura do Curso de Licenciatura em Letras Libras e novos concursos foram realizados para composição do corpo docente. Dentre os novos ingressantes estava a professora Lídia da Silva, a qual agregou ao Curso sua experiência profissional e formação acadêmica na área de Libras como segunda língua (L2) para ouvintes. Assim, a partir do interesse comum desses dois professores, em 29 de outubro de 2015, com anuência e apoio da coordenação do Curso, na pessoa da professora Sueli Fernandes e com aprovação nas instâncias deliberativas, inicia-se o Programa de extensão Núcleo de Ensino de Libras (NEL). O NEL parte da premissa da disseminação da Libras na cidade de Curitiba e, para tanto, sua identidade visual, que é abaixo ilustrada, procura demonstrar esse conceito:

\section{Imagem 1 - Logo do Programa de Extensão}

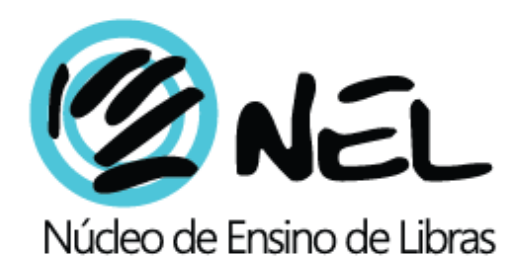

Fonte: arquivo pessoal das autoras

O círculo na cor azul representa a mão que é a principal referência à Libras e os dedos em cor preta procuram demonstrar o movimento de espalhar. A partir dessa conceitualização inicial, o Programa ganhou um sinal em Libras, que está abaixo representado:

Imagem 2 - Sinal do NEL

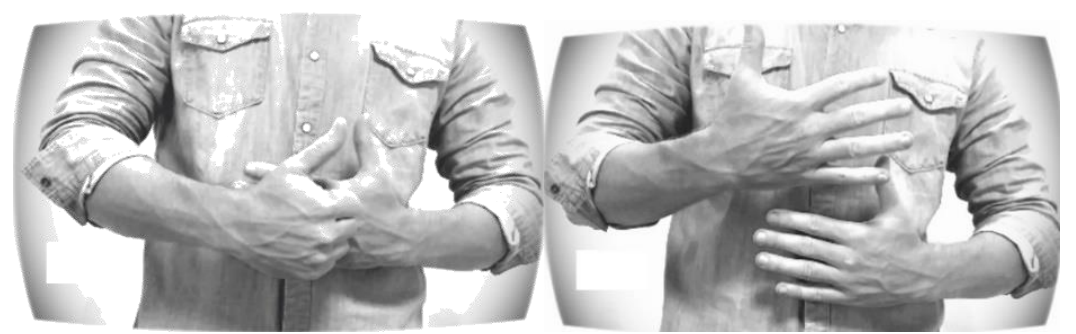

Fonte: arquivo pessoal das autoras 
Práticas extensionistas relacionadas à Libras como L2 para ouvintes: relato e avaliação da experiência

É sobre esse Programa de extensão que discorreremos neste texto. Para tanto, nesta primeira parte, relataremos brevemente a execução dos cursos, dos eventos, dos projetos e dos produtos vinculados ao Programa, bem como destacaremos a indissociabilidade com a pesquisa. $\mathrm{Na}$ seção seguinte, apresentaremos a proposta de Cristofoletti e Serafim (2020), que norteou a metodologia de avaliação das ações extensionistas. Posteriormente, apresentaremos a avaliação propriamente dita.

\section{O relato da experiência}

Pessoas surdas, segundo Skliar (1998), não se referem simplesmente àquelas que têm perda auditiva, mas sim às pessoas que se inserem em um contexto grupal onde a comunicação se dá, essencialmente, pela experiência visual e pela utilização da Libras (no caso do Brasil). Sendo assim, para a maioria dos surdos, a Libras caracteriza-se como sua primeira língua (L1), e a língua majoritária do Brasil, o português, caracteriza-se como L2, ou seja, aquela língua não adquirida naturalmente e que exige esforço para que ocorra o aprendizado de sua versão escrita - já que há impedimento sensorial para que aprendam a versão falada/oralizada. Tal contexto aponta para um problema de exclusão social no Brasil, haja vista que são poucas as pessoas não surdas que conhecem a Libras e poucos são os cidadãos surdos que (por inúmeras questões, entre as quais as metodológicas) aprendem a língua portuguesa. A educação linguística atuando com a disseminação da Libras é uma das possibilidades de reversão desse quadro de exclusão e é nessa esteira que se sustenta o Programa de extensão NEL.

O NEL oferece cursos de extensão de Libras, nos níveis básico, intermediário e avançado, os quais são anuais, gratuitos e contam com $100 \mathrm{~h}$ da carga horária em cada nível. De modo geral, as aulas são distribuídas em 25 encontros de 4h de duração, aos sábados pela manhã.

Essa prática extensionista com Libras como L2 já proporcionou o ensino dessa língua de minoria para mais de 700 pessoas ouvintes, pois, em média, recebe 240 alunos por ano para o curso de Libras, nos níveis básico, intermediário e avançado.

O público-alvo do NEL é composto, prioritariamente, por ouvintes da comunidade externa que são incluídas mediante processos seletivos regidos por Editais. Normalmente, esses Editais são amplamente divulgados e, por isso o NEL costuma receber muitas inscrições, como em 2016, em que cerca de quatro mil pessoas pleitearam vaga para o nível básico. O ingresso nos níveis intermediário e avançado ocorrem mediante banca de avaliação e nivelamento e, nesse processo, os estudantes de Letras Libras atuam como avaliadores. Após a seleção, os cursistas realizam o pagamento de uma taxa de matrícula ( $\$$ \$ 30,00), a qual vai para uma conta controlada pela Proplan (Pró-Reitoria de Planejamento, Orçamento e Finanças), cujo empenho se dá, normalmente, com gastos de coffee-break e 
que são gerenciados pelo ordenador de despesas do Setor de Ciências Humanas da UFPR. Os ministrantes dos cursos, que normalmente atuam em duplas, são estudantes surdos e ouvintes de Letras Libras. A participação desses acadêmicos no processo de extensão pode se dar de diferentes formas:

1) Participação mediante Programa de Voluntariado Acadêmico (PVA): o corpo discente de Letras Libras tem a oportunidade de, voluntariamente, atuar na atividade extensionista, sob a orientação dos coordenadores do NEL. A atuação, que é regulamentada pela Resolução 76/09 da UFPR, não gera vínculo empregatício e confere horas de atividades formativas complementares aos estudantes para integralizarem o currículo ${ }^{1}$;

2) Participação mediante articulação com o ensino: a licenciatura em Letras Libras conta com disciplinas ${ }^{2}$ metodológicas voltadas à formação de professores de Libras como L2, sendo que nessas o ementário prevê a "prática como componente curricular" e 50\% da carga horária da disciplina é voltada a "estágio obrigatório". Portanto, os estudantes matriculados nas referidas disciplinas produzem suas atividades práticas e de estágio no NEL, ministrando aulas em uma das turmas e/ou desenvolvendo materiais;

3) Participação mediante oferecimento de bolsa de extensão: a Pró-Reitoria de Extensão e Cultura (PROEC) da UFPR, por meio de chamada interna, viabiliza a participação de bolsista em Programas de extensão e, quando contemplado, o NEL realiza as seleções que se dão mediante publicação de Editais, os quais são disponibilizados no site institucional ${ }^{3}$.

Quanto à questão da organização pedagógica dos cursos do NEL, apresentamos o Quadro 1:

Quadro 1 - Organização pedagógica dos Cursos do NEL

\begin{tabular}{|c|c|c|c|}
\hline ORGANIZAÇÃO & $\begin{array}{l}\text { NÍVEL } \\
\text { BÁSICO }\end{array}$ & $\begin{array}{c}\text { NÍVEL } \\
\text { INTERMEDIÁRIO }\end{array}$ & $\begin{array}{c}\text { NÍVEL } \\
\text { AVANÇADO }\end{array}$ \\
\hline Objetivo geral & $\begin{array}{l}\text { Levar os aprendizes a } \\
\text { comunicarem-se em } \\
\text { Libras a respeito de } \\
\text { temas socioculturais que } \\
\text { circundam a comunidade } \\
\text { surda, atentando-se aos } \\
\text { aspectos lexicais e } \\
\text { gramaticais do idioma. }\end{array}$ & $\begin{array}{l}\text { Levar os aprendizes à } \\
\text { compreensão e à } \\
\text { produção de textos } \\
\text { sinalizados a respeito de } \\
\text { temas socioculturais que } \\
\text { circundam a comunidade } \\
\text { surda, atentando-se aos } \\
\text { aspectos lexicais, } \\
\text { gramaticais e discursivos }\end{array}$ & $\begin{array}{c}\text { Levar os aprendizes à } \\
\text { compreensão e à } \\
\text { produção de variados } \\
\text { gêneros textuais, } \\
\text { atentando-se aos } \\
\text { aspectos lexicais, } \\
\text { gramaticais, discursivos e } \\
\text { sociolinguísticos do } \\
\text { idioma. }\end{array}$ \\
\hline
\end{tabular}

${ }^{1}$ Para fins de registro histórico, destacamos os ministrantes dos primeiros cursos, oferecidos em 2016, que atuaram voluntariamente: Sirlene de Carvalho Matos Pereira, Lorianny de Andrade Gabardo, Elissane Zimmermann Dyniewicz, Luiz Gustavo Paulino de Almeida, Flávia Trevisan Ferreira, Thiago Steven dos Santos, Paula Cristina Roque, Angela de Fátima Girardi Stelmacki, Jonatas Rodrigues Medeiros, Guilherme Serpa Andrade, Thiago Alexandre Hubie, Carlos Alexandre Silvestri. Além desses, a estagiária Arlete G. Zilli e o professor Maurício Lima dos Santos.

${ }^{2}$ Lib063 - Ensino de Libras como L2 - I (120h) e Lib067 - Ensino de Libras como L2 - II (120h)

${ }^{3}$ Disponível em http://www.letraslibras.ufpr.br/nel/ 


\begin{tabular}{||c|c|c|c||}
\hline \hline & & do idioma. & \\
\hline \multirow{3}{*}{$\begin{array}{c}\text { Encaminhamento } \\
\text { metodológico }\end{array}$} & $\begin{array}{c}\text { Apresentação de insumos } \\
\text { linguísticos autênticos, } \\
\text { ensino de vocabulários, } \\
\text { ensino da Gramática e } \\
\text { sistematização final. }\end{array}$ & $\begin{array}{c}\text { Leitura, interpretação de } \\
\text { texto, análise linguística } \\
\text { do texto. Criação e } \\
\text { produção textual. }\end{array}$ & $\begin{array}{c}\text { Apresentação inicial, } \\
\text { leitura, produção inicial, } \\
\text { análise metalinguística, } \\
\text { pesquisa e produção final } \\
\text { do gênero textual. }\end{array}$ \\
\hline
\end{tabular}

Fonte: elaboração própria

Para cada nível, um material didático é oferecido em formado PDF junto com vídeos em Libras, além dos próprios recursos didáticos que são elaborados pelos ministrantes.

Além do público-alvo predominante, em 2017, através do Programa houve oferecimento de oficinas de Libras para familiares de $\operatorname{surdos}^{4}$ e, em 2018, oficinas de Libras para crianças ouvintes, sendo que para ambas os materiais e encaminhamentos foram inteiramente preparados pelos acadêmicos do Letras Libras. A página da rede social ${ }^{5}$ do NEL ilustra as participações nas oficinas, oferendo registros e memórias. A oficina de Libras para crianças ocorreu em razão de realização de atividades para a disciplina Lib067 - Ensino de Libras como L2 - II (120h) da graduação em Letras Libras.

Fora as questões pedagógicas, o Programa também conta com a mobilização da UFPR para atender à logística, já que pelo menos 10 salas $^{6}$ e equipamentos de mídia são utilizados aos sábados pela manhã. O aporte administrativo ocorre com a coordenação do NEL e com um estudante ${ }^{7}$ de Letras Libras que auxilia nos procedimentos funcionais. Além disso, o início de cada ano é marcado pela realização da "aula inaugural”, que reúne os cursistas e ministrantes de todas as turmas para receberem instruções acerca do funcionamento das aulas, dos critérios de certificação e orientações diversas. Nessa ocasião, os estudantes do Letras Libras organizam a recepção dos cursistas e dirigem a programação do evento que, geralmente, conta com mesa diretiva com pronunciamentos em Libras para os quais há interpretação simultânea para português, dinâmicas e apresentações culturais. Neste dia, a UFPR disponibiliza o técnico do estúdio do Letras Libras, Jimmy Leão, para realizar captação de imagens do evento.

Uma apresentação dos cursos do NEL foi roteirizada, filmada e editada por um dos alunos do nível avançado, Eduardo Nascimento Rohn - que é técnico de edição na UFPR - e por meio dela há uma síntese com amostras reais das práticas extensionistas citadas e, por isso, a indicamos aqui. Entretanto, o Programa não se configura apenas como espaço do curso de Libras, mas também como

\footnotetext{
${ }^{4}$ Ministrado pelas estudantes Amanda Regina Silva e Joana Bonato Melegari

${ }^{5}$ https://www.facebook.com/NELUFPR1

${ }^{6}$ Até 2018, os cursos ocorriam no Setor de Ciências Jurídicas e após passaram para o Setor de Educação Profissional e Tecnológica.

${ }^{7}$ Em 2018 a aluna Rafaella Raissa Oliveira Spena atuou como supervisora e no ano de 2019 a aluna Márcia dos Santos Rezende desempenhou esse papel.
} 
Práticas extensionistas relacionadas à Libras como L2 para ouvintes: relato e avaliação da experiência

articulação de outras iniciativas extensionistas, entre elas eventos e projetos.

Quanto aos eventos de extensão, destacamos três principais: "Cine Debate", "Simpósio para Aprendizes de Libras" e o "Dia do Surdo".

O "Cine debate" ocorreu em 2016 e contou com a participação de mais de 200 pessoas externas à UFPR, dentre as quais muitos surdos. Na ocasião, houve a exibição do filme Central do Brasil, traduzido para Libras pelo intérprete Jonatas Rodrigues Medeiros, que é técnico administrativo na UFPR e toda a programação do evento (desde a mesa de abertura, a solenidade, a palestra proferida em referência ao filme, a condução das discussões no grande grupo e as pipocas) foi organizada pelos cursistas e pelos estudantes do Letras Libras. Durante todo o evento, Libras figurou como a língua “oficial” e teve interpretação simultânea para português, a qual também foi realizada pelos extensionistas.

O "Simpósio para Aprendizes de Libras" ocorreu em 2018 e contou com a participação de 300 pessoas nas oficinas pedagógicas, que tiveram o objetivo de auxiliar o desenvolvimento linguístico na L2. O evento recebeu aporte financeiro do Setor de Ciências Humanas (ao qual o Curso de Letras Libras está vinculado) para sua realização e teve a participação da Profa. Dra. Rachel Sutton Spence (UFSC), que realizou a conferência de abertura, e do Prof. David Quinto Pozzos (Texas University at Austin) com a palestra proferida por videoconferência. A realização desse evento se deu em decorrência da prática como conteúdo programático da disciplina Lib063 - Ensino de Libras como L2 - I (120h) da graduação em Letras Libras.

O "Dia do Surdo" é um evento que ocorre anualmente, no dia 26 de setembro, data comemorada em todo Brasil pela comunidade surda. Por ocasião do evento, os cursistas convidam pessoas surdas para estarem presentes no NEL e participarem da programação cultural, artística e festiva que é promovida e divulgada por eles em conjunto com os estudantes da graduação em Letras Libras. Em 2018 o NEL promoveu uma passeata pelas ruas da cidade, mencionando o setembro azul, cantando e sinalizando coros que aludiam à data. $\mathrm{Na}$ ocasião, conversavam com as pessoas que passavam pelas ruas e lhes explicavam sobre a Libras e o Dia do Surdo. Tal ato gerou a elaboração de um videoclipe com a música autoral "Por um Brasil Bilíngue", de membro da comunidade externa (Marcos Simioni) e, em 2019, a TV UFPR vinculou a realização da comemoração como uma matéria oficial $^{9}$.

Os projetos de extensão vinculados ao Programa NEL são três, a saber:

1) Ensino de Libras como L2: Por meio deste projeto, os extensionistas desenvolvem materiais de Ensino de Libras como L2 e os implementam com os cursistas do NEL. A título de

\footnotetext{
${ }^{8}$ Disponível em https: / www.youtube.com/watch?time continue $=2 \& v=W k Z r 1 G b y A p A \& f e a t u r e=e m b \log 0$

${ }_{9}^{9}$ Disponível em https://www.youtube.com/watch?v=pOlpTNYj5Hc
} 
ilustração destacamos as sequências didáticas que foram desenvolvidas pela aluna Ghenifer Caroline de Morais Emmerick, no ano de 2019, para os cursistas do intermediário:

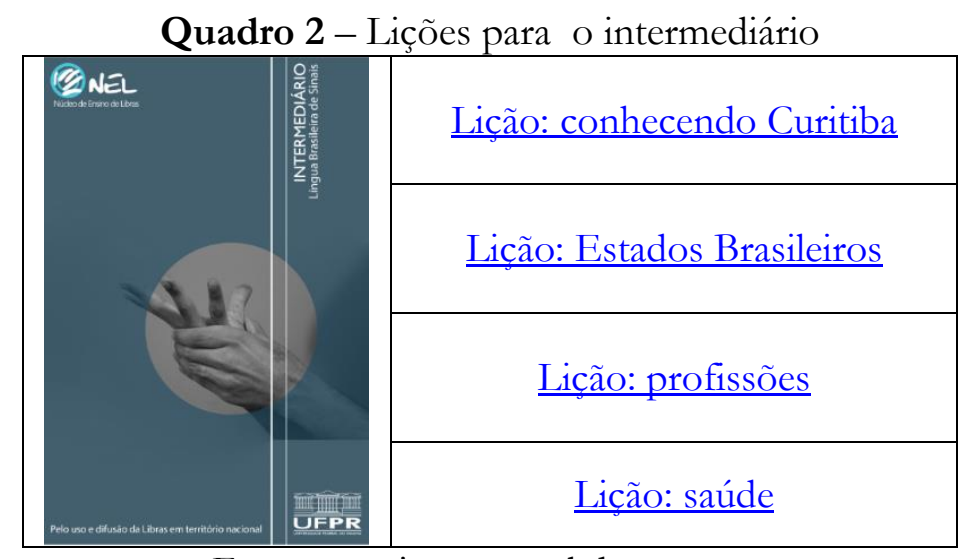

Fonte: arquivo pessoal das autoras

2) Aprendizagem de Libras como L2: Esse projeto tem por objetivo oferecer materiais que colaborem com a aprendizagem de vocabulários da Libras por aprendizes ouvintes. Em 2019, a bolsista Lidiane Rozendo Fernandes dos Santos elaborou sequências de atividades sobre vocabulários de baixa frequência nas áreas de Matemática e Geografia, que foram oferecidas aos cursistas do avançado. As sequências didáticas foram organizadas a partir de APP (apresentação, prática e produção), seguidas de pré- e pós-teste e o signwriting (escrita de sinais) figurou como recurso de auxílio à memória.

3) Avaliação de Libras como L2: O objetivo desse projeto é o desenvolvimento de materiais de avaliação de fluência em Libras e aplicação com cursistas do nível avançado do NEL. Em 2019, houve o desenvolvimento do TEFLUL - Teste de Fluência em Libras, o qual teve a participação do aluno Lucas Gomes Albuquerque.

O Programa também gerou o website SAELL (Sistema de Apoio aos Estudos da Libras como L2) ${ }^{10}$. Essa realização contou com a geração de conteúdos pela bolsista Juliane da Silva Bento, do Letras Libras (e outros estudantes por ela coordenados), e pela prestação de serviços extensionista que ocorreu devido ao apoio financeiro recebido da PROEC da UFPR. Contou também com a colaboração dos técnicos administrativos Rodrigo Madalozzo Bordini e Eduardo Nascimento Rohn, para programação do site e edição dos vídeos nele alocados, respectivamente. Como resultado, tem-se uma plataforma que se destina a dois públicos principais: aprendizes e professores de Libras como L2. Na parte voltada aos aprendizes, o site contém vocabulários, exercícios gramaticais, diálogos e entrevistas. Já para professores, o SAELL reserva palestras instrucionais e tradução de artigos científicos da área. O produto de extensão veio sanar uma questão lacunar que é presente em relação ao acesso de materiais em Libras, haja vista que a maioria das fontes de consulta disponíveis (tais como vídeos do YouTube,

${ }^{10}$ Disponível em www.saell.ufpr.br 
aplicativos e dicionários) são de qualidade questionável já que não são geridas por uma instituição de ensino, como uma universidade.

No que tange aos princípios extensionistas, o Programa destaca-se, especialmente, pela indissociabilidade com a pesquisa. Ilustra essa afirmação a criação do Grupo de Pesquisa GEPELS (Grupo de Estudo e Pesquisa de Libras como L2) e da linha de pesquisa "Libras como L2" no GPELIN/CNPq/UFPR. Nesses grupos ocorre a análise das instruções, materiais, produtos e ações propostas pelos projetos de extensão já explanados, bem como coleta de dados no NEL - como o caso da tese de doutorado de Silva (2018), que tratou da sinalização dos alunos do nível avançado. Quantitativamente, no ano de 2020, a produtividade dos membros dos grupos de pesquisas se deu com dois trabalhos de conclusão de curso, dois trabalhos de iniciação científica, três apresentações de trabalhos em eventos acadêmicos e quatro publicações de artigos científicos em periódicos. Uma compilação dos principais trabalhos desenvolvidos foi apresentada em comunicação coordenada na Semana de Letras da UFPR de $2020^{11}$. Ademais houve a organização de um evento on-line que reuniu pesquisadores de várias partes do Brasil em oito noites de discussão sobre a temática ${ }^{12}$.

Dado o espaço para relatar as experiências extensionistas da área de Libras como L2 para ouvintes que são desenvolvidas no âmbito da UFPR, vamos passar à sua avaliação. Antes disso, porém, na próxima seção apresentaremos os pressupostos metodológicos que a nortearam.

\section{METODOLOGIA}

A extensão universitária, junto ao ensino e à pesquisa é uma das funções da Universidade e é por várias razões - de importância incontestável, tanto no que concerne à formação acadêmica como no que diz respeito ao aspecto social. Sua avaliação, entretanto, ainda carece de aprimoramento, tanto sobre os indicadores e métricas quanto sobre a metodologia de mensuração dos seus impactos. Sendo assim, Abreu (2020) comenta:

A extensão universitária, estabelecida como parte do tripé indissociável da universidade pública proposto pela Constituição Federal de 1988 (CF/1988), é a ponte entre universidade e comunidade e deve se tornar, cada vez mais, instrumento para a formulação de políticas públicas efetivas para a transformação social. Apesar do relevante papel dado pela $\mathrm{CF} / 1988$ à extensão universitária, a Política Nacional de Extensão Universitária revela que ainda não foram estabelecidos critérios objetivos para avaliação dos projetos e programas de extensão (PEACs) no âmbito das universidades. Os PEACs devem atender aos objetivos propostos pela Política Nacional de Extensão, a qual esclarece que a universidade tem o compromisso de ser

\footnotetext{
${ }^{11}$ https://www.youtube.com/watch?v=Qo7OQtvu9aE\&list=PLosbrFJgLWjSwKyxOf-UfDE3k7wuPSsST\&index=3

12 http://www.letraslibras.ufpr.br/nel/seminario-online-de-libras-como-12-para-ouvintes/
} 
instrumento de mudança social e deve atuar na busca pelo diálogo com a sociedade. (ABREU, 2020, p. 8)

Tendo essa problemática em mente e tomando por base o relato de experiência que foi expressado de forma bastante exploratória, tomamos o caso do Programa NEL para avaliá-lo. Para tanto, buscamos uma proposta de avaliação que contemplasse as várias vertentes da extensão de modo a romper com a velha prática de centralidade de um aspecto ou indivíduo e, por isso, o modelo analítico de Cristofoletti e Serafim (2020), por sua amplitude de dimensões, foi considerado válido. A análise será tecida tomando por base as categorias de avaliação da extensão propostas por Cristofoletti e Serafim (2020) e abaixo reproduzidas:

Quadro 3 - Dimensões de avaliação das práticas extensionistas

Dimensões Metodológicas/Analíticas
1. Quem faz a extensão?
2. A quem se destina a atividade extensionista?
3. Quais atividades materializam a extensão praticada e como ela se institucionaliza no
interior da universidade?
4. Quais os objetivos da extensão e por que se faz a extensão?
5. Que tipo de conhecimento é estendido/transferido/construído e como isso é
realizado (metodologias e pedagogias utilizadas)?
6. Quais são os "impactos", produtos e benefícios das atividades de extensão para a
comunidade externa e para aniversidade?
7. Como as atividades são legitimadas socialmente e dentro da universidade?
8. Qual a função social e compromisso social da universidade?
9. Qual é a inserção contextual e histórica da experiência extensionista?

Fonte: Elaboração pelas autoras, com base em Cristofoletti e Serafim (2020)

\section{AVALIAÇÃO DA EXPERIÊNCIA}

A análise se inicia com as duas primeiras dimensões propostas por Cristofoletti e Serafim (2020) e avalia que as práticas extensionistas relacionadas à Libras, como L2, que têm sido promovidas pelo Programa NEL, ocorrem mediante escassez de recursos humanos profissionais (professores e técnicos) e vasto envolvimento do corpo discente do Letras Libras da UFPR (dimensão 1). Quanto à dimensão 2, nota-se que as atividades extensionistas destinam-se a membros ouvintes da comunidade externa (no caso dos cursos), à comunidade interna do Letras Libras (no caso de projetos) e à comunidade surda Curitibana (no caso dos eventos). Como se pode perceber, por meio do relato anteriormente apresentado, esses atores extensionistas só puderam fazer e receber a extensão dado o apoio institucional, tanto no plano acadêmico (inserção do Programa no ensino) quanto no estrutural e orçamentário.

Cristofoletti e Serafim (2020) apontam que a terceira dimensão de avaliação deva dedicar-se à 
análise das atividades que materializam a extensão praticada e como elas são institucionalizadas no interior da universidade. A respeito disso, sinteticamente apresentamos nossa avaliação desse aspecto:

Quadro 4 - A institucionalização das atividades extensionistas

\begin{tabular}{|c|l|}
\hline $\begin{array}{c}\text { ATIVIDADES EXTENSIONISTAS } \\
\text { MATERIALIZADAS PELO PROGRAMA } \\
\text { NEL }\end{array}$ & \multicolumn{1}{|c|}{ CARÁTER INSTITUCIONAL } \\
\hline Cursos de Libras e eventos & $\begin{array}{l}\text { Aprovação em instâncias deliberativas, formalização no } \\
\text { Sistema Integrado de Gestão Acadêmica (SIGA) da UFPR, } \\
\text { emissão de certificados, administração orçamentária por } \\
\text { unidade competente. Elaboração, aprovação e registro dos } \\
\text { planos de ensino das disciplinas Lib063 e Lib067 com } \\
\text { programa contemplando as atividades práticas a serem } \\
\text { realizadas pelos estudantes. }\end{array}$ \\
\hline Projetos de extensão & $\begin{array}{l}\text { Elegibilidade para participação de editais internos. } \\
\text { Aprovação no pleito de apoio financeiro e solicitação de } \\
\text { bolsas de extensão. }\end{array}$ \\
\hline Produtos de extensão & $\begin{array}{l}\text { O principal produto gerado pelo Programa, o SAELL, tem } \\
\text { um domínio e hospedagem da UFPR, com contas de e-mail } \\
\text { e manutenção institucionais. }\end{array}$ \\
\hline
\end{tabular}

Fonte: elaboração própria

Constatamos que disseminar a Libras a um número cada vez maior de pessoas ouvintes e, consequentemente, incluir as pessoas surdas em diferentes instâncias sociais, é o principal objetivo das ações extensionistas do NEL e, nesse sentido, a avaliação da quarta dimensão analítica de Cristofoletti e Serafim (2020) fica posta. Esse objetivo vai ao encontro do viés político da extensão universitária o qual visa "promover a interação transformadora entre a universidade e outros setores da sociedade" (FORPROEX, 2013). O grupo de pessoas que teve sua realidade transformada evidencia sua afinidade com a inclusão social, seu sentimento de pertencimento ao NEL e sua identidade de aliado da comunidade surda que de forma autônoma propõem atividades e encontros sociais e até a confecção de camisetas com a marca do NEL.

Podemos afirmar que a respeito da dimensão 5, o NEL tem viabilizado a construção de três tipos de conhecimento, a saber: acadêmico, técnico e pluriversitário. O primeiro foi destacado no relato quando se demonstrou a articulação com a pesquisa. O conhecimento técnico tem sido construído e reflete-se na formação profissional dos acadêmicos do Letras Libras, uma vez que, eles têm desenvolvido habilidades necessárias à prática docente e têm agregado repertório diferenciado em relação àqueles que atuam em sala de aula apenas após a graduação ou limitam-se ao cumprimento da carga horária do estágio obrigatório. Também tem havido geração de conhecimento pluriversitário, o qual, diferentemente do conhecimento universitário, é contextual, dialogal, transdisciplinar, heterogêneo, subjetivo, humano, cidadão e emancipatório (SILVA; CAMPANI; PARENTE, 2018). A 
presença da população externa à Universidade, que anualmente, enfrenta filas quilométricas e que aguarda madrugada a dentro para tentar uma vaga no curso de Libras, certamente, tem ampliado rupturas com o saber elitizado e nos tem feito repensar os compromissos e concepções que temos assumido dentro dos muros da academia. Apesar da diversidade das práticas extensionistas, podemos afirmar que, de modo geral, as metodologias e pedagogias utilizadas pelo Programa assentam-se no princípio da interação dialógica, uma vez que as atividades vinculadas consideram as demandas apresentadas, as diferentes áreas de conhecimento e do contexto e o compartilhamento do planejamento, da execução e da avaliação das ações.

Quanto à sexta dimensão, a proposta de Cristofoletti e Serafim (2020) é que avaliemos "que diferença a atividade extensionista fez na realidade das comunidades, grupos ou instituições participantes"? A esse respeito, podemos identificar os impactos diretos e indiretos do Programa. Os diretos são aqueles relacionados à concretização do objetivo de disseminar Libras a um grande número de pessoas ouvintes (bem como a formação dos estudantes e a produção de conhecimento específico derivadas dessa ação); os indiretos são aqueles conhecidos por observações e relatos. Os impactos diretos podem ser ilustrados pelos recortes da avaliação de 2018:

Quadro 5 - Avaliação 2018

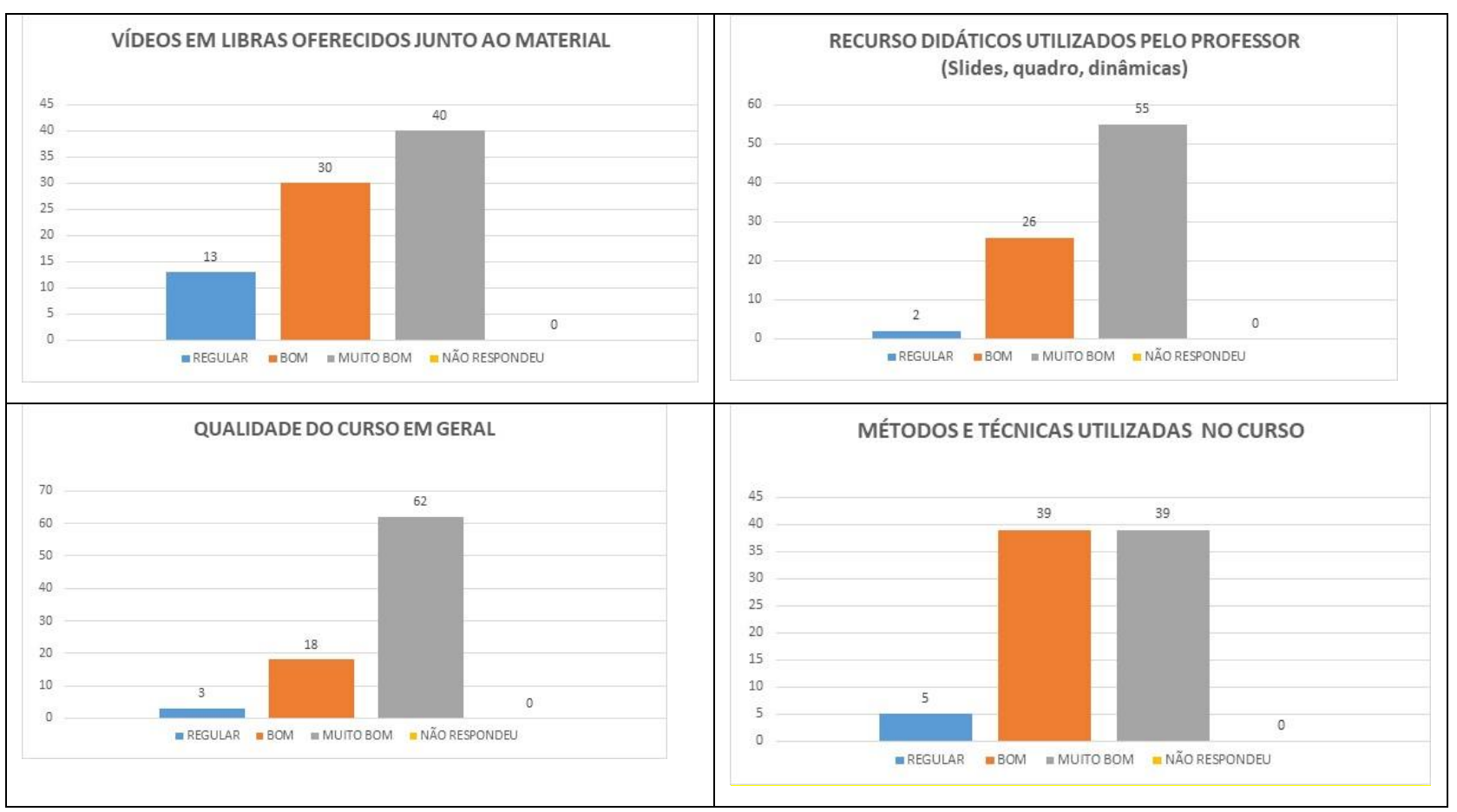

Fonte: arquivo pessoal das autoras

Além desses dados, há também as considerações tecidas pelos cursistas de 2019: 
Sou agradecida pelo NEL ter me dado essa oportunidade de aprendizagem, consegui me superar a cada aula, agradeço as professoras maravilhosas, dedicadas e responsáveis. (ALUNO/A NEL A, 2019)

Estou muito feliz com o curso com a oportunidade de participar desse curso pela Federal, esse foi um ano cheio de descobertas em relação à Libras, algo com que eu nunca tive contato na minha vida, mas foi uma experiência riquíssima e espero que no intermediário seja tão bom quanto foi esse ano. (ALUNO/A NEL B, 2019)

Esses relatos também parecem evidenciar que as atividades do NEL são legitimadas socialmente (dimensão 7). Ainda quanto à sexta dimensão, apresentamos os dados abaixo que comparam os resultados do pré-teste e do pós-teste dos alunos do nível avançado após a realização das sequências didáticas dos vocabulários de baixa frequência de matemática e geografia e evidenciam impacto na aprendizagem:

Quadro 6 - Resultado da aprendizagem de vocabulário

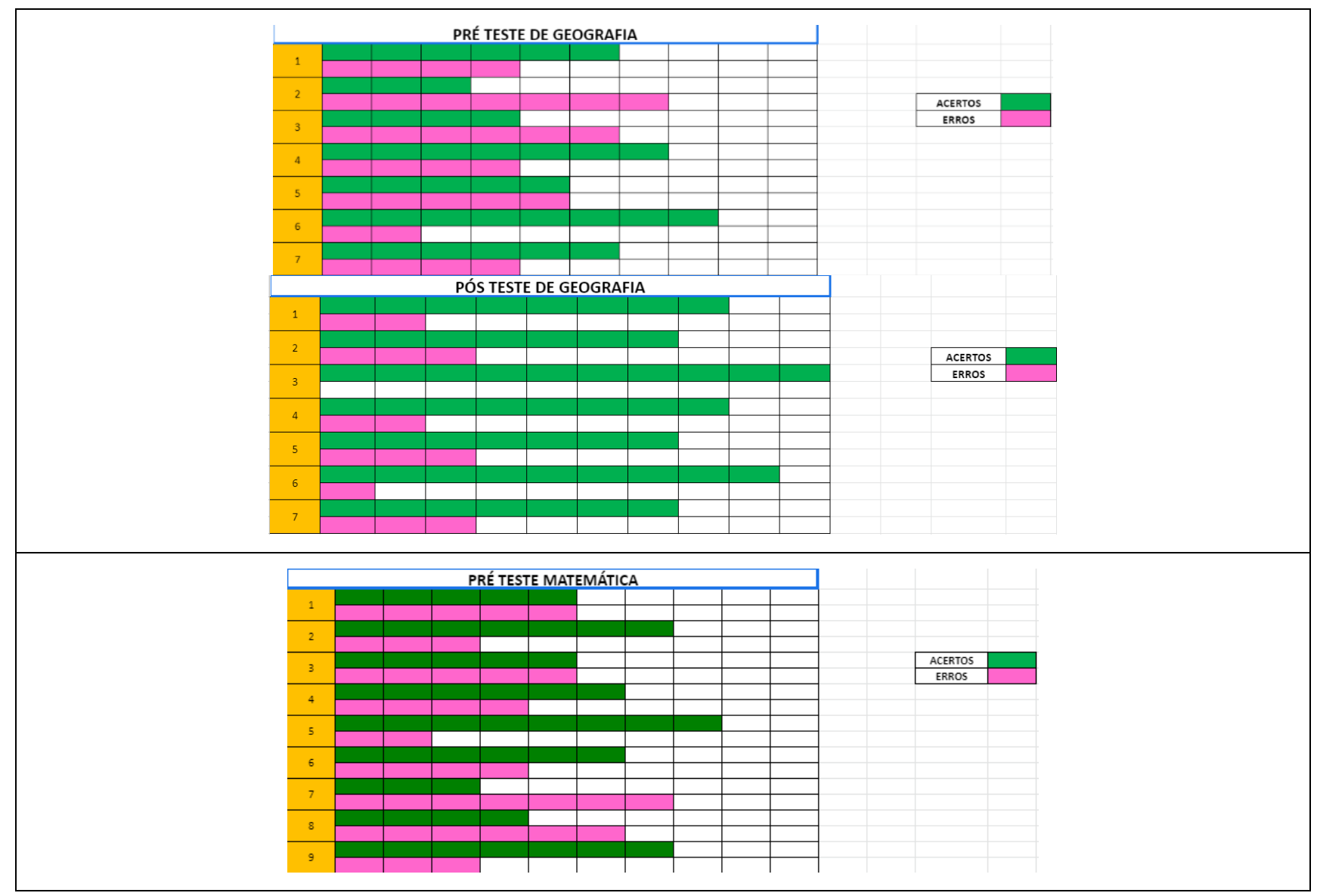



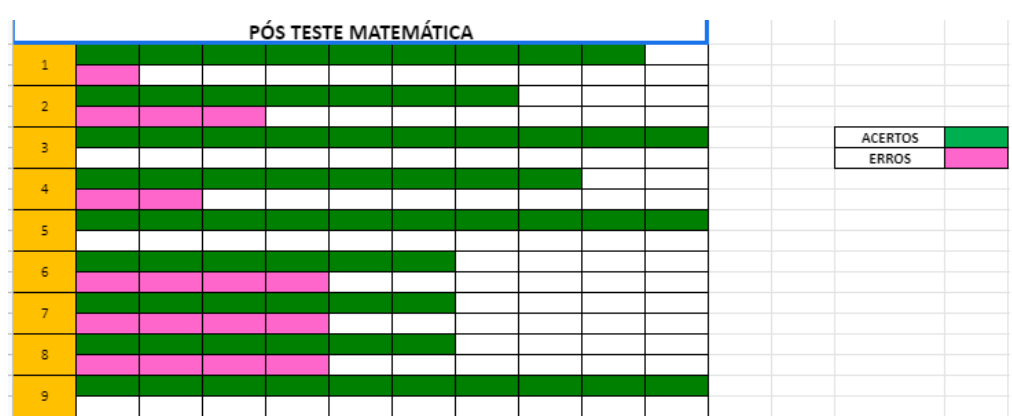

Fonte: dados do projeto "Aprendizagem de Libras como L2"

A respeito dos impactos indiretos avaliamos positivamente o incentivo ao ingresso na universidade pública, pois muitos são os cursistas do NEL que, após o ciclo de aprendizado do idioma, vislumbram a possibilidade de ingresso no curso de graduação em Letras Libras e percebem que têm competência linguística para serem aprovados no vestibular que é em Libras. Ao adentrarem o ensino superior, essas pessoas estão frente à oportunidade de desenvolvimento social e profissional, bem como ao acesso ao saber acadêmico.

Há também a questão da qualificação no idioma. Muitos são os familiares de surdos e profissionais que já sabem se comunicar em Libras e que procuram o NEL para se aperfeiçoarem no idioma, assim como também é comum que ouvintes que tenham sido aprovados no vestibular em Letras Libras e que não possuem fluência necessária para acompanhar as aulas da graduação, tenham acompanhamento do NEL para seu nivelamento. Há ainda a questão do desenvolvimento linguístico dos próprios docentes ouvintes que atuam como ministrantes dos cursos, os quais imbuídos da missão de representar a língua aos seus alunos empenham-se nos estudos e tornam-se mais fluentes em Libras. O ambiente linguístico do NEL possibilita a imersão na língua e o desenvolvimento efetivo no idioma.

O protagonismo surdo é, igualmente, um importante impacto causado pelo NEL. O Programa de Extensão, pela configuração das suas práticas que privilegiam a Libras e a representatividade surda, tem fomentado não só a disseminação da cultura surda, mas favorecido a inclusão social efetiva. Ademais, através das relações interpessoais (que são plurais e únicas ao mesmo tempo), impactos globais são percebidos na visão de mundo tanto de surdos quanto dos ouvintes.

O NEL também é um espaço para desenvolvimento de habilidades técnicas, pois, além da habilidade pedagógica que é desenvolvida pelos ministrantes do curso, muitos atores extensionistas pela participação no Programa encontram oportunidade de desenvolver outras habilidades técnicas. A gravação e edição de vídeo proporcionada pelo SAELL é um exemplo. A “aula inaugural” e os demais eventos promovidos pelo Programa são espaço de fomento das habilidades tradutórias e organizacionais para os estudantes. Com certeza, o princípio do impacto na formação do estudante se 
Práticas extensionistas relacionadas à Libras como L2 para ouvintes: relato e avaliação da experiência

faz presente pelas práticas extensionistas desenvolvidas no NEL. Por fim, um impacto significativo para a produção audiovisual (vídeos e site) e as produções artísticas.

A legitimação interna mencionada pela dimensão 7 pode ser observada pela constante propagação institucional, pelo suporte recebido quanto às realizações do Programa e pela aderência das suas práticas extensionistas no curso de Letras Libras. A fim de ilustrar o discurso corrente, segue divulgação da UFPR a esse respeito do NEL:

\section{Imagem 1 - Divulgação da UFPR}

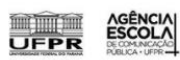

\section{IGUALDADE}

OPORTUNIDADE

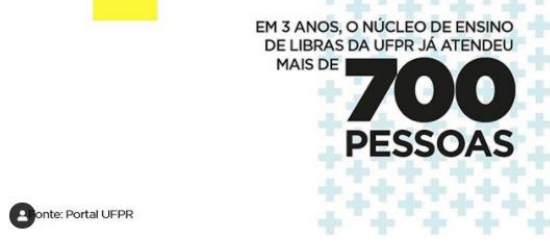

Fonte: Rede social Instagram da Agência Escola de Comunicação da UFPR

Ao que parece, as práticas extensionistas que têm sido desenvolvidas pela área, em alguma medida, refletem o compromisso social da universidade tal como aponta a oitava dimensão de Cristofoletti e Serafim (2020). Dizemos isso, pois o Programa NEL tem também incursão na cultura e tem desenvolvido valores relativos à democracia e à cidadania. Observa-se, portanto, que essa Universidade está oportunizando o exercício da empatia e da reflexão sobre a ética das relações humanas a todos os envolvidos no Programa. Além disso, constatamos que, da forma que tem atuado na extensão, essa Instituição tem demonstrado responsabilidade social por meio de atividades do Programa que fazem com que cada vez mais pessoas ouvintes aprendam a Libras, de modo a propiciar a ampliação do universo de interação das pessoas surdas; assim, estas últimas podem ter sua dignidade humana respeitada e a igualdade de oportunidade atendida.

Enfim, resta avaliar que, de acordo com Cristofoletti e Serafim (2020), na menção à dimensão 9, o contexto social e político estão imbricados nas práticas extensionistas do NEL, uma vez que no Brasil a legislação, por meio da Lei 10.436/2002 e do decreto 5626/2005, tem incentivado que o poder público apoie o uso e a difusão da Libras. É nesta esteira que se configuram as ações do Programa, ou seja, a extensão insere-se neste amplo contexto histórico, político e social, a fim de perseguir o ideal que 
Práticas extensionistas relacionadas à Libras como L2 para ouvintes: relato e avaliação da experiência

pode concretizar-se quando os cidadãos que não ouvem puderem, livre e abertamente, falar com pessoas ouvintes em Libras; pois aí, então, estar-se-á frente ao retrato de uma sociedade pacífica, justa e inclusiva.

\section{CONCLUSÃO}

O relato das experiências extensionistas de 2016 a 2021 no Programa NEL assinala a consistência da oferta de cursos de Libras, de nível básico, intermediário e avançado que são motivadores das proposições de eventos de extensão. Os projetos vinculados ao Programa, da mesma forma, viabilizam o desenvolvimento de ações extensionistas que colaboram aos referidos cursos. O produto SAELL, por sua vez, caracteriza-se como ferramenta de suporte aos estudos dos envolvidos no Programa NEL. Nesse amalgama, identifica-se também o ensino e a pesquisa da área de Libras como L2.

A avaliação das práticas extensionistas do NEL, segundo as dimensões metodológicas e analíticas propostas por Cristofoletti e Serafim (2020), aponta que estudantes e professores interessados na área de Libras como L2 têm se engajado com as diversas atividades do Programa e, por isso, têm construído variados conhecimentos junto à comunidade interna e externa da UFPR. Essas atividades, por serem estruturadas, interrelacionadas, legitimadas social e institucionalmente, têm trazido impactos significativos a todos os atores do processo.

Assim, pensamos que à medida que o Programa se fortalecer, suas práticas extensionistas igualmente se desenvolverão. Por fim, o NEL parece refletir as premissas da UFPR, quais sejam: democratização do saber, da postura crítica e do espaço público, gratuito, de qualidade, democrático e inclusivo.

Considerando o exposto, esperamos pela continuidade do Programa e que essa exposição colabore, em alguma medida, para o aprimoramento das suas ações.

\section{AGRADECIMENTOS}

Agradecemos imensamente a todos os estudantes do Letras Libras da UFPR, especialmente, às turmas de 2015, 2016 e 2017, por terem participado com tanto afinco desse arrojado programa de extensão permitindo assim sua concretização.

\section{REFERÊNCIAS}

ABREU, Caroline Figueiredo Belo. Avaliação da extensão universitária: reflexões sobre o fazer 
Práticas extensionistas relacionadas à Libras como L2 para ouvintes: relato e avaliação da experiência

extensionista na Universidade de Brasília. (Dissertação de Mestrado Profissional). Universidade de Brasília, Brasília, 2020. Disponível em https://repositorio.unb.br/handle/10482/38851. Acesso em 13 maio de 2021.

CRISTOFOLETTI, Evandro Coggo; SERAFIM, Milena Pavan. Dimensões Metodológicas e Analíticas da Extensão Universitária. Educação \& Realidade. V 5, N 1, 2020. Disponível em: https://seer.ufrgs.br/educacaoerealidade/article/view/90670. Acesso em 13 maio de 2021

FÓRUM DE PRÓ-REITORES DE EXTENSÃO DAS INSTITUIÇÕES PÚBLICAS DE EDUCAÇÃO SUPERIOR BRASILEIRAS. Avaliação da Extensão Universitária: práticas e discussões da Comissão Permanente de Avaliação da Extensão. Organização: Maria das Dores Pimentel Nogueira. Belo Horizonte: FORPROEX/CPAE; PROEX/UFMG, 2013 (Coleção Extensão Universitária; v.8).

SILVA, L. Fluência de ouvintes sinalizantes de libras como segunda língua: foco nos elementos da espacialização. 2018. Tese (Doutorado em Linguística) - Universidade Federal de Santa Catarina, Florianópolis, 2018. Disponível em: https://repositorio.ufsc.br/handle/123456789/193780. Acesso em: 3 jun. 2021.

SILVA, Rejane Maria Gomes, CAMPANI, Adriana, PARENTE, Paulina Maria Mendes. A extensão universitária como pilar epistemológico da indissociabilidade na Universidade. In: SILVA, Rejane Maria Gomes; HOLANDA, Virginia Célia Cavalcante (Org). A expansão do ensino superior em debate: Sobral, $\quad$ Ceará, $2018 . \quad$ Disponível $\quad$ em http://www.uvanet.br/edicoes_uva/gera_xml.php?arquivo=expansao_ensino_superior. Acesso 13 maio de 2021.

SKLIAR, Carlos. A surdez: um olhar sobre as diferenças. Porto Alegre: Mediação, v. 3, 1998.

Recebido em: 05/06/2021

Aceito em: 13/12/2021 